\title{
Para Além do Mito da Democracia Racial: A Questão Educacional no Pensamento de Gilberto Freyre
}

\author{
Beyond the Myth of Racial Democracy: \\ The Educational Question in Gilberto Freyre's Thought
}

Amurabi Oliveira

\begin{abstract}
Resumo: Apesar da constante revisão que o legado de Gilberto Freyre (1900-1987) tem recebido nos últimos anos, há um aspecto em sua obra ainda pouco explorado: a questão educacional. $O$ que pode ser compreendido a partir de dois aspectos: a atuação de Freyre no campo educacional, e a presença da questão educacional ao longo de sua vasta obra, ainda que de forma dissolvida. Neste artigo proponho-me a analisar a questão educacional no pensamento de Freyre a partir de dois aspectos: o primeiro remete à forma que a questão educacional se apresenta em seu trabalho, o que incluirá também uma breve contextualização sobre sua atuação nesse campo; o segundo seria uma reflexão sobre o modo que a relação entre raça e educação aparece em sua obra.
\end{abstract}

Palavras Chaves: Gilberto Freyre; Pensamento Social Brasileiro; Raça e Educação; Antropologia da Educação; Antropologia Brasileira.

Abstract: Despite the constant review that the legacy of Gilberto Freyre (1900-1987) has received in recent years, there is one aspect in his work still little explored: the educational issue. What can be understood from two aspects: Freyre's work in the educational field, and the presence of educational issue throughout his vast work, albeit in a dissolved form. In this article I propose to examine the educational issue in Freyre's thought from two aspects: the first refers to how the educational issue is presented in his work, which will also include a brief contextualization of his work in this field; the second would be a reflection on how the relationship between

Latitude, Vol. 10, no 1, pp. 112-133, 2016

DOI: https://doi.org/10.28998/2179-5428.20160105 
Para além do mito da democracia racial: a questão educacional no pensamento de Gilberto Freyre

race and education appear in his work.

Key Words: Gilberto Freyre; Brazilian Social Thought; Race and Education; Anthropology of Education; Brazilian Anthropology.

\section{Introdução}

Tornou-se lugar comum afirmar que a interface entre a Antropologia e a Educação é algo incipiente no Brasil. Trata-se realmente de um campo em processo de constituição (GUSMÃO, 2009), todavia tem sido olvidado no debate acadêmico o fato de que tal diálogo não constitui um fenômeno novo, nem mesmo quando temos em mente o contexto mais local. Isto é válido tanto se considerarmos a criação dos Laboratórios de Psicologia e Antropologia Pedagógica junto às Escolas Normais, instituições responsáveis pela formação de professores ${ }^{1}$ no começo do século XX (OLIVEIRA, 2013), quanto se pensarmos que a reflexão antropológica acerca dos processos educacionais, o que não necessariamente se restringiu a um olhar sobre a escola. Tal questão se faria presente, ainda que de forma dissolvida por vezes, na obra de alguns dos principais cânones da Antropologia brasileira. Neste sentido, esse trabalho visa contribuir para essa discussão ao trazer à tona um aspecto da obra de Gilberto Freyre (1900-1987) ainda pouco explorado: o debate sobre a questão educacional.

Nesse artigo, entretanto, não me proponho a realizar apenas um esmiuçamento do debate educacional na vasta obra freyreana, pois compreendo que esse exercício, ainda que bastante frutífero e necessário, situa-se muito aquém das demandas que têm emergido no campo educacional. Pretendo a partir disso levantar alguma reflexão sobre a atualidade das questões postas por Freyre para pensarmos a relação entre

1 Entre meados do século XIX e a primeira metade do século XX as Escolas Normais foram as principais instituições formadoras de professores no Brasil, apenas nos anos de 1930 surgiram os primeiros cursos de formação de professores em nível superior, e somente a partir de 1939 com a criação da Universidade do Brasil, que contava com a Faculdade Nacional de Educação, é que se passou a criar as licenciaturas dentro do modelo que se convencionou denominar como " $3+1$ ", no qual deveria se cursar primeiro um curso de bacharelado e posteriormente complementá-lo com uma formação pedagógica, para assim habilitar o egresso para a docência, esse modelo se estendia inclusive ao curso de pedagogia. 
raça $^{2}$ e educação na realidade brasileira, ainda que este se constitua certamente em um dos campos mais minados na academia brasileira, especialmente se considerarmos que a elaboração e defesa do chamado "mito da democracia racial" é recorrentemente atribuído a Gilberto Freyre (MOTTA, 2000).

Tem havido nos últimos anos um processo de profunda revisão do legado de Freyre, o que tem incluindo não apenas os autores brasileiros como também os chamados brazilianists (LEHMANN, 2008). Porém, a questão educacional ainda não tem sido encarada como um ponto relevante a ser destacado em seu obra, o que tem sido realizado de forma ainda bastante pontual, ademais, utilizar-se daquele que é considerado (ou acusado) o elaborador do "mito da democracia", como já afirmei, para pensar as relações raciais no campo educacional brasileiro é algo tido quase como uma heresia em determinados espaços acadêmicos.

Não se trata em absoluto de produzir um artigo que visa unicamente polemizar um debate, mas sim de iluminar um aspecto da obra de Freyre pouco explorado e mesmo desconhecido por antropólogos e educadores, que em última instância se desdobram em uma contribuição para amadurecermos e qualificarmos a discussão sobre a constituição do campo da Antropologia da Educação no Brasil.

Para uma melhor organização das ideias presentes nesse texto ele será dividido em duas partes: a) na primeira realizarei uma análise sobre como que a questão educacional se apresenta no trabalho de Freyre, o que incluirá também uma breve contextualização sobre sua atuação nesse campo; b) na segunda me proponho a realizar algumas reflexões iniciais, dado os limites desse trabalho, sobre como a relação entre raça e educação aparece em sua obra, o que nos possibilita também vislumbrarmos sua atualidade.

\section{Gilberto Freyre e a Educação: algumas pistas}

Para uma melhor compreensão do pensamento de Freyre é inegável fazer referência ao fato de que ele nasceu no seio de uma família

2 Não se trata de pensar raça aqui como um dado biológico, mas sim como uma construção social, ademais essa categoria apesar de assumir múltiplos sentidos ao longo dos trabalhos de Freyre, é sempre pensada em relação à dimensão cultural, notadamente havendo um exercício de distinção entre raça e cultura. 
Para além do mito da democracia racial: a questão educacional no pensamento de Gilberto Freyre

aristocrática do nordeste açucareiro, já no final do século XIX, e de fato seu saudosismo mostra-se pulsante em todos seus escritos. Não à toa para ele a saudade se constituía como um método empático de fazer reviver um tempo morto (VILLAS BOAS, 2006), o que se articulava também com sua intuição, que seria um dos alicerces de seu fazer científico (FREYRE, 1968).

Acredito que para um mais completo entendimento acerca de como um determinado autor pensa a questão educacional é de suma importância analisarmos como foi seu próprio processo de educação. No caso do menino Gilberto é bastante conhecida a forte influência em seu aprendizado escolar de seu pai Alfredo Freyre, que era educador, que o orientou desde cedo para a vida intelectual.

Ademais sua passagem pelo colégio Americano Batista do Recife, no qual despendeu boa parte de sua infância e adolescência, também lhe deixou marcas intelectuais e afetivas. Para Larreta e Guicci (2007) as experiências vivenciadas nesta instituição, marcada pelos rigorosos métodos de alguns de seus professores, encontram-se na origem de muitos comentários de Freyre sobre a falta de infância das crianças brasileiras. Nessa escola:

(...) além da vida comum de um aluno teve o encargo de lecionar latim para os alunos menos adiantados, o que em parte fazia por obrigação, já que nem ele nem o irmão pagavam mensalidades em virtude da ligação do pai, que fora diretor da escola, com a instituição. Seus registros apontam para uma aversão aos métodos rígidos e mesmo violentos assumidos por alguns docentes, o que certamente influenciou a posição que passa a defender com relação ao ensino, aspecto que fica ainda mais evidente em uma das poucas experiências docentes que teve, quando lecionou Sociologia na Escola Normal de Pernambuco, no final dos anos de 1920. (OLIVEIRA, 2015a, p. 205206).

Outro ponto relevante que merece ser rememorado é que foi por meio das ligações desta instituição escolar que Freyre seguiu para os 
Estados Unidos, tendo em vista que a Universidade de Baylor, em Waco Texas, tinha uma tradição em receber alunos vindos de Recife. O fato de ter ido para o Sul dos Estados Unidos teve um impacto decisivo no modo como ele interpretou o Brasil, e principalmente as relações raciais que aqui se desenvolveram, pois. Ele encontrou uma região também marcada pelo latifúndio, pela monocultura, pela família patriarcal e pelo trabalho escravo, de tal modo que a região Sul desse país tornou-se o contraponto constante no processo de compreensão do Brasil (PALLARES-BRUKE, BRUKE, 2009), ainda que as proximidades históricas e sociais possibilitassem principalmente destacar as características idiossincráticas em termos étnicos e sociais que havia na América Portuguesa.

Seus estudos de pós-graduação, no entanto, foram desenvolvidos em um centro maior, no caso junto na Universidade de Columbia em Nova York, na qual desenvolveu seu trabalho em nível mestrado ${ }^{3}$. Não sem menor relevância é importante lembrar que em inúmeros de seus trabalhos ele ressaltou enormemente a vivência acadêmica em Columbia, bem como as influências intelectuais que lá sofreu. É bastante conhecida a passagem no prefácio da primeira edição de Casa Grande $\mathcal{E}$ Senzala na qual afirma que "O professor Franz Boas é a figura de mestre de que me ficou até hoje maior impressão. Conheci-o nos meus primeiros dias em Colúmbia." (FREYRE, 2005, p. 31). No entanto Motta (2008) chega a questionar em que medida ela representa a realidade, tendo em vista que Franz Boas (18581942) não foi orientador no sentido formal do termo de Freyre e que este realizou seu mestrado em História Social, não em Antropologia.

Motta e Fernandes (2013) levantam como hipótese que Freyre, pelo menos desde a publicação de Casa-grande $\mathcal{E}$ Senzala, teria optado por destacar o legado de Boas em detrimento de seu relacionamento com Carlton Hayes (1882-1964), que fora seu orientador nos estudos de pósgraduação. Para estes interpretes, a filiação que Freyre passou a reivindicar se ligava a questões subjetivas e objetivas do autor, que se refeririam tanto à possibilidade de se destacar academicamente ao se aproximar da Sociologia e da Antropologia, que eram ciências novas e que possuíam poucos catedráticos no Brasil, quanto à influência real que Boas exerceu sobre sua obra, em que pese outras múltiplas influências como a de Charles Maurras

3 Seu trabalho de mestrado em História Social intitulou-se Social life in Brazil in the middle of the 19th century e foi publicado no periódico Hispanic American Historical Review volume 5. 
Para além do mito da democracia racial: a questão educacional no pensamento de Gilberto Freyre

(1868-1952).

Tendo em vista a formação que ele recebeu em Columbia fica evidente que a sua vocação transdisciplinar estava posta desde já, uma vez que realizou cursos diversos nesta instituição. Segundo seu histórico escolar ele fez seis cursos de História, dois de Lei Pública, dois de Sociologia, dois de Antropologia, um de Inglês e um de Belas-artes ${ }^{4}$.

Obviamente que considerando os limites e o foco desse trabalho não me caberia realizar uma análise esmiuçada de sua trajetória escolar, porém creio que os elementos trazidos aqui pontualmente são de suma importância para pensarmos a relação entre experiência escolar e a forma como ele irá pensar a Educação, tendo em vista a posição que o autor assumirá com relação aos métodos mais tradicionais e rígidos de ensino, o que é influenciado por um lado pelas más experiências que teve com estes métodos na infância e juventude, por outro, pelo contato que teve com a forma como o ensino era concebido nos Estados Unidos.

Também é relevante destacar as condições objetivas que estavam postas quando Freyre voltou para o Brasil em 1923. Entre os anos de 1920 e 1930 ocorreram intensas mudanças políticas e sociais no país, o que incluiu Reformas Educacionais capitaneadas por alguns intelectuais, como foi no caso da Pernambuco aquela posta a cabo por Carneiro Leão (1887-1966), que introduziu a Sociologia no curso de formação de professores junto à Escola Normal de Pernambuco. Freyre foi em 1928 indicado para assumir a cátedra dessa disciplina, e ainda que tenha havido uma experiência anterior em 1925 no Colégio Pedro II no Rio de Janeiro com Delgado de Carvalho (1884-1980), Freyre reivindica para si o pioneirismo de ter sido o primeiro a lecionar Sociologia de forma articulada com o trabalho de campo (FREYRE, 2003). Tratava-se de um momento de ascensão das Ciências Sociais no campo acadêmico brasileiro. Esta foi uma das poucas experiências de Freyre como docente, tendo em vista que toda sua vida acadêmica é marcada por uma trajetória profundamente heterodoxa.

No trabalho de Meucci (2015a) há uma análise detalhada tanto da prática docente que Freyre desenvolveu junto à Escola normal, quanto junto à Universidade do Distrito Federal, já na década seguinte, na qual ela aponta que seus planos de ensino indicavam um desejo profundo de evitar qualquer forma de "enciclopedismo", inovando metodologicamente ao

4 O histórico de seu curso de mestrado está disponível para consulta na Fundação Gilberto Freyre. 
buscar estabelecer uma profunda relação entre conhecimento teórico e a realidade social mais próxima. Penso que a partir da análise sobre como Freyre desenvolveu sua prática pedagógica podemos chegar a algumas considerações acerca de como ele compreendeu que deveriam ser desenvolvida a experiência escolar.

No programa de disciplina da cátedra de Sociologia Freyre realiza a seguinte ponderação acerca de seu método de ensino:

As alunas deverão conservar dois cadernos: um de notas, registrando as explicações dadas na classe; outro de retalhos de jornaes, com artigos, notícias, etc. sobre factos e actualidades de interesse sociológico. O material reunido nesses cadernos de retalhos será objecto de discussão e motivo para troca de ideias uma vez por semana. (FREYRE, 1930, $\mathrm{s} / \mathrm{p})$

A esta prática somar-se-iam ainda a observação de fatos cotidianos "de interesse sociológico" e a realização de inquéritos, "social survey" e visitas aos principais serviços públicos, bairros pobres, usinas etc. $\mathrm{Na}$ Universidade do Distrito Federal, atuando junto ao curso de Ciências Sociais, deu prosseguimento os princípios pedagógicos que iniciou no Recife (MEUCCI, 2015a), e ainda que o foco do curso fosse a formação de professores, o sociólogo e antropólogo pernambucano manteve a pesquisa como um elemento indissociável do ensino, o que reflete também uma dada concepção de formação docente.

Esse ponto no qual ele sugere a articulação entre teoria e realidade social não me parece que se restrinja a este período de sua vida, pois ele retoma tais questões na palestra que faz às professoras rurais em Pernambuco (FREYRE, 1957), bem como quando analisa a relação entre Antropologia e a Reforma do Ensino (FREYRE, 1973, p. 139).

Tal articulação deveria se dá por meio de um ensino que embora tivesse o livro como um de seus elementos centrais não deveria ser livresco. Mais uma vez percebe-se aí a influência tanto de suas experiências escolares iniciais, ao rejeitar a possibilidade de um ensino desconectado da realidade social e baseado em métodos de ensino rígidos, bem como do ensino vivenciado nos Estados Unidos, cujas marcas intelectuais são 
Para além do mito da democracia racial: a questão educacional no pensamento de Gilberto Freyre

bastante profundas no autor (PALLARES-BRUKE, 2005), ficando este último ponto ainda mais evidente na palestra que ele profere sobre o Ensino de Ciências Sociais naquele país. Nas palavras do autor:

Mas o estudo das ciências sociais não fica nos livros. O de sociologia e o de antropologia social, principalmente, incluem o chamado "field work" ou trabalho de campo; o "social survey" ou sondagem sociológica limitada a certo grupo ou área social; as entrevistas sociológicas; o levantamento e interpretação de estatísticas; e, ainda, a chamada "social case history" que é o documento colhido no vivo, com toda a objetividade possível e todo o escrúpulo científico. Essas pesquizas, como visitas a fábricas, a penitenciarias, a serviços públicos, a hospitais, como a colheita de dados antropometricos em bairros característicos, escolas, oficinas; essa variedade de experiências e de contactos humanos, por assim dizer dramatisam o estudo das ciências sociais nos Estados Unidos, dando ao estudante o gosto de descobrir elle proprio os fatos, o sabor quasi físico de aventura entre os elementos básicos da vida social. (FREYRE, 1934, p. 57).

Estas questões também são explicitadas quando Freyre publica em 1945 o livro intitulado Sociologia: introdução ao estudo dos seus princípios, tendo em vista que ele se baseou em larga escala nas preparações e anotações realizadas para os cursos que ministrou. Quase ao final do livro, já em seus apêndices, há algumas "sugestões para exercícios", no qual o autor coloca as seguintes questões:

O grande inimigo, no uso didático deste livro, seria o aprendizado apenas memorizador, professores e alunos, lembrados de que "a letra mata e o espírito vivifica", deverão levar seu entendimento do texto além das formulações escritas, buscando, em todas as etapas, compreender o que o autor quis dizer. 
O professor facilitará essa tarefa pelo tipo de exercícios e trabalhos que venha a passar. Sugere-se, por exemplo, a elaboração de resumos e sumários dos diferentes capítulos, devendo o aluno apontar e delimitar os problemas discutidos.

Para temas e exercícios escritos, ou em perguntas para provas de verificação, é importante evitar fórmulas que ocasionem simples definições, preferindo, pelo contrário, levar o aluno a fazer seus próprios relacionamentos e raciocínios.

(...).

Ainda interessante, como forma prática de trabalho, seria que alunos e professores procurassem, em rápidas pesquisas de campo, aplicação prática dos conceitos de Sociologia. (FREYRE, 2009, p. 499-500).

Considerando tais aspectos, acredito que Freyre a partir de sua prática foi um reformador do ensino (OLIVEIRA, 2014), o que estava assentado em sua compreensão de Antropologia e Sociologia em grande medida. Ainda que bastante eclipsada essa passagem de sua carreira, é importante destacar que não se encerrou aí seu vínculo mais ativo com a educação, pois com a criação do Centro Brasileiro de Pesquisas Educacionais na década de 1950, que constituiu uma forma não mais reeditada no Brasil de encontro entre as Ciências Sociais e a Educação (BOMENY, 2003), ele se tornou diretor de uma de suas unidades regionais, o Centro Regional de Pesquisas Educacionais do Recife.

É digno de nota o fato de que as pesquisas desenvolvidas por este centro enquanto esteve sob sua responsabilidade centraram-se essencialmente nas questões educacionais, chegando mesmo a ser construída em 1962 uma Escola Experimental, dedicada a testar propostas e atividades curriculares e materiais didáticos desenvolvidos pelo Centro (MEUCCI, 2015b), o que difere substancialmente do que ocorreu no CBPE de modo geral, no qual foram desenvolvidas inúmeras pesquisas que não possuíam ligação direta com o objeto educacional (SILVA, 2002).

Ainda que realizado de forma bastante resumida creio que o resgate desse aspecto da obra de Freyre é relevante inclusive para refletirmos sobre a constituição da Antropologia da Educação no Brasil, tendo em vista que 
Para além do mito da democracia racial: a questão educacional no pensamento de Gilberto Freyre

estes elementos nos possibilitam desmistificar a ideia de que a presença dos antropólogos brasileiros na seara educacional seria algo recente, no caso de Freyre sua presença nos remete ao final dos anos de 1920. No próximo tópico refletirei acerca de como a questão educacional aparece de forma dissolvida na obra freyreana, especialmente no que se refere à relação entre raça e educação no Brasil, o que nos possibilita vislumbrarmos a atualidade das questões por ele suscitadas.

\section{Raça, Educação e Democracia Étnica}

Adentrar no debate sobre a questão racial no pensamento freyreano é sempre um exercício arriscado, tendo em vista toda a polêmica que envolve a recepção de suas ideias ao menos desde a publicação de CasaGrande E Senzala em 1933, que obteve como respostas as mais diversas reações (FREYRE, 1968).

Para uma compreensão mais completa acerca do trabalho de Freyre e de sua recepção é necessário destacar o contexto intelectual daquele momento, no qual a questão racial se coloca como um dos eixos centrais para o desvelamento do enigma chamado Brasil. De acordo com Bastos (2006), o ensaísmo dos anos de 1920 possuía duas temáticas centrais: a questão da cultura e a busca da identidade nacional. Ainda segundo Bastos, os autores desse período procuravam "inventar a cultura" para legitimar a "invenção" da identidade nacional, e teria sido Freyre aquele que realizou um salto nos estudos sociais ao conseguir articular esses dois elementos.

Mas as questões postas por Freyre além de inovadoras em inúmeros aspectos, o que inclui a dimensão metodológica de sua pesquisa (BURKE, 1997), também se opunham a ideias que vinham sendo amplamente defendidas nos meios intelectuais brasileiros, compreendidas como arianistas. De forma contrária a estas ideias o antropólogo e sociólogo pernambucano propunha uma interpretação do Brasil enquanto país miscigenado no plano biológico e cultural. Para Cardoso (2013), Freyre criou um mito sobre o Brasil no qual gostamos de nos ver, porém, acredito que há pontos presentes na interpretação do autor de Casa-Grande $\mathcal{E}$ Senzala que vão para além de uma dimensão mitológica.

Sua oposição às ideias arianistas a partir do conceito de miscigenação articulada com a hipótese de que houve aqui uma escravidão mais amena em alguns aspectos que em outras partes do mundo, marcada 
por uma certa "doçura" na relação entre portugueses - que seriam povos também miscigenados situados entre a Europa e África em termos culturais e étnicos - e os negros transformados em escravos,gerou uma enxurrada de críticas ao que se convencionou denominar de "mito da democracia racial", do qual seria elaborador e defensor. Mas como nos indica Lehmann (2008), o que Freyre propôs inúmeras vezes foi que o Brasil poderia estar a caminho de uma "democracia étnica ou racial".

Considerando, portanto, a centralidade que a questão racial assume na obra de Freyre desde o princípio de seu trabalho procurarei compreender como ele percebe a relação entre raça e educação, o que não é uma tarefa fácil dado o caráter disperso que esta questão aparece. Ademais, como pontua Motta (2009, p. 149): “Gilberto Freyre jamais completou a tradução, em conceitos claros e distintos, em proposições articuladas, com sequência e consequência, de sua muito poderosa intuição sobre o que faz o Brasil ser o Brasil", o que complexifica ainda mais o objetivo desse trabalho.

Já em Casa-Grande E Senzala a educação aparece como um elemento continuamente presente na realidade do engenho, nessa unidade quase total que abarcava também as práticas pedagógicas, afinal, era ali também que se aprendiam "as primeiras letras". Chamo a atenção para o fato de que se encontra aí um dos elementos chaves para compreendermos a relação entre raça e educação no Brasil que é a "co-educação" entre negros e brancos, uma vez que a possibilidade de que crianças pertencentes a raças diferentes fossem educadas juntas era uma das singularidades que encontraríamos no Brasil se comparado com outros países que vivenciaram a escravidão. Mais que isso, este seria um dos pilares basilares para vislumbrarmos no Brasil a possibilidade de caminharmos para uma democracia étnica.

No entanto, há de se considerar as tensões que estavam postas nos processos educacionais brasileiros, uma vez que na interpretação de Freyre os jesuítas não contribuíram para a formação de uma democracia étnica no Brasil, justamente por negarem o sistema de co-educação entre negros e brancos, para o autor em Interpretação do Brasil 5 :

5 Esta obra refere-se a um conjunto de conferências realizadas por Freyre em 1944 em universidades norte-americanas, portanto, os textos foram pensados tendo em vista o público estrangeiro. Apenas em 1947 Interpretação do Brasil é traduzido e lançado no Brasil e quatro anos depois em Portugal. 
Para além do mito da democracia racial: a questão educacional no pensamento de Gilberto Freyre

(...) os jesuítas realizaram uma obra valiosíssima no Brasil como missionários e educadores; mas o seu sistema excessivamente paternalista e ao mesmo tempo autocrático de educar os índios desenvolveuse às vezes em oposição às primeiras tendências esboçadas no Brasil no sentido de uma democracia étnica e social. (FREYRE, 2001, p. 94).

E mais adiante ele ainda afirma que:

(...) concentraram-se os jesuítas em desenvolver um sistema de educação que trouxesse sob a sua influência os filhos dos colonos ricos e também as crianças indígenas. E o fato é que nas suas escolas, escolas que logo se fizeram famosas, o latim e a retórica que nelas se ensinavam tanto eram obrigatórios para os filhos de branco como para os filhos de índio.

Negros e mulatos não eram, entretanto, geralmente aceitos nessas escolas, razão porque não se deve contar o jesuíta entre as influências que favoreceram, no Brasil, o amalgamento das raças e a democratização social e étnica da Colônia. (Idem, p. 110-111).

Há nessas passagens questões bastante centrais para o que me proponho a analisar neste trabalho, tendo em vista que aparece nessa passagem a certeza de que houve no Brasil um "amalgamento das raças" e que a educação teria um papel relevante para tanto, uma vez que desde o princípio esse seria um espaço bastante plural em termos étnicos, havendo nos primeiros séculos nesses colégios comandados por jesuítas caboclos, filhos de normandos, filhos de portugueses, mamelucos, meninos louros, sardentos, pardos, morenos, cor de canela etc., todavia "Só os negros e moleques parecem ter sido barrados das primeiras escolas jesuíticas. Negros e moleques retintos." (FREYRE, 2005, p. 501), porém sem restrições aos pardos .

Em todo o caso, apesar da crítica aos jesuítas, devido ao fato de não 
terem aberto espaço para os negros em seus colégios, o autor reconhece também os aspectos positivos que decorreram de suas práticas pedagógicas, especialmente no que diz respeito à outra forma de coeducação praticada por estes, uma vez que aparentemente teria havido uma igualdade no processo de educação em seus colégios entre os séculos XVI e XVII de índios e portugueses, europeus e mestiços, caboclos e meninos órfãos vindos de Lisboa.

Terá sido assim a vida nos colégios dos padres um processo de co-educação das duas raças - a conquistadora e a conquistada: um processo de reciprocidade cultural entre os filhos da terra e meninos do reino. Terão sido os pátios de tais colégios um ponto de encontro e de amalgamento de tradições indígenas com as europeias; de intercâmbio de brinquedos; de formação de palavras, jogos e superstições mestiças. O bodoque de caçar passarinho, dos meninos índios, o papagaio de papel, dos portugueses, a bolsa de borracha, as danças etc., terão aí se encontrado, misturando-se. A carrapeta - forma brasileira de pião - deve ter resultado desse intercâmbio infantil. Também a gaita de canudo de mamão e talvez certos brinquedos com quenga de coco de castanha de caju. (FREYRE, 2005, p. 224).

Lamenta que posteriormente tenha havido um processo de segregação entre indígenas e branco, o que deixa evidente a postura do autor contrária a qualquer forma de segregação com base em questões étnicas, que seria, desse modo, empobrecedoras culturalmente. Mas ainda que a educação possa ser compreendida como um ponto nodal da produção dessa "democracia étnica", que ele admite se tratar de um "tipo ainda imperfeita de democracia social" (Idem, p. 198), isso não ocorre sem sobressaltos e tensões, tendo em vista que:

Os padre-mestres e os capelães de engenho, que, depois da saída dos jesuítas, tornaram-se os 
Para além do mito da democracia racial: a questão educacional no pensamento de Gilberto Freyre

principais responsáveis pela educação dos meninos brasileiros, tentaram reagir contra a onda absorvente da influência negra, subindo das senzalas às casas-grandes; e agindo mais poderosamente sobre a língua dos sinhô-moços e das sinhazinhas do que eles, padre-mestres,c om todo o seu latim e com toda a sua gramática; com todo o prestígio das suas varas de marmelo e das suas palmatórias de sucupira. (Ibidem, 2005, p. 417).

Considerando tais aspectos compreendo que a educação na perspectiva do autor contribuiu para a construção de uma democracia étnica no Brasil não apenas por meio da co-educação entre negros e brancos, mas também pela interpretação de culturas, que sendo uma das características distintivas do país também se fazia presente nos processos de aprendizagem. Sendo assim, a onipresença africana na cultura brasileira estender-se-ia à escola e aos processos de aprendizagem de forma mais ampla. A educação brasileira estaria, desse modo, decididamente marcada pela interpenetração de culturas.

Essa relevância do elemento africano para os processos educacionais só é possível ante a percepção de Freyre de que a cultura brasileira é formada não apenas por aqueles tidos como "cultos", mas também por analfabetos, tanto brancos quanto negros ${ }^{6}$. Como ele nos indica: "Certos autores, dos que se ocupam superficialmente dos problemas de cultura, mostram especial tendência para exagerar a importância da alfabetização, como sinal de superioridade absoluta dos povos considerados civilizados sobre os rústicos." (FREYRE, 2011, p. 84), e segue completando o raciocínio:

Nobres, reis, príncipes mercadores, doutores em Filosofia, advogados, médicos, padres, judeus sefárdicos, cientistas, todos contribuíram, cada um a seu modo, para a colonização portuguesa do Brasil.

6 Isso não significa que Freyre compreendida que todos os negros africanos aqui transformados em escravos eram incultos, pelo contrário, ele destaca especialmente os negros de origem maometana entre os quais a prática da leitura e da escrita seria recorrente, algo que se diferenciava inclusive dos próprios senhores de engenho, por vezes destituídos dessa prática (Freyre, 2001, 2005, 2011). 
Mas tornamos a dizer: nessa colonização a força criadora mais constante parece vir sendo a formada pelos camponeses analfabetos, alguns deles com sangue africano do norte: árabe, mouro e mesmo negro. (Idem, p. 85).

Mais que isso, quando Freyre se refere aos colégios, especialmente os jesuítas, ele faz referência sempre a sua severidade no trato com os alunos. ele fala de um abuso criminoso da fraqueza infantil, e nesse ponto encontraremos mais uma conexão com a questão racial no país, tendo em vista que:

Houve verdadeira volúpia em humilhar a criança, em dar bolo em menino. Reflexo da tendência geral para o sadismo criado no Brasil pela escravidão e pelo abuso do negro. O mestre era um senhor todopoderoso. Do alto de sua cadeira, que depois da Independência tornou-se uma cadeira quase de rei, com a coroa imperial esculpida em relevo no espaldar, distribuía castigos com o ar terrível de um senhor de engenho castigando negros fujões. Ao vadio pinha de braço abertos, ao que fosse surpreendido dando uma risada alta, humilhava com um chapéu de palhaço na cabeça para servir de mangação à escola inteira; a um terceiro, botava de joelhos sobre grãos de milho. Isto sem falarmos da palmatória e da vara - esta, muitas vezes com um espinho ou um alfinete na ponta, permitindo ao professor furar de longe a barriga da perna do aluno. (FREYRE, 2005, p. 507-508).

Sendo assim, a escola seria ao mesmo tempo um espaço de "amalgamento" das relações raciais, contribuindo para a construção de uma democracia étnica, mas também refletiria as tensões de uma sociedade escravista e profundamente sádica. Penso que a ideia de "equilíbrio de antagonismos" que permeia toda a obra de Freyre é fundamental para compreendermos sua interpretação sobre o universo escolar, pois, de fato o 
Para além do mito da democracia racial: a questão educacional no pensamento de Gilberto Freyre

professor e o aluno, nestes termos, formariam polos antagônicos, mas também complementares, tal como o senhor e o escravo, o pai e o filho.

Sem embargo, a instrução formal só teria passado a ganhar um lugar de destaque na complexa sociedade que se constituiu nos Trópicos a partir de seu processo de urbanização mais intenso, afinal, o latifúndio era anteriormente a base da economia canavieira. Nesse ponto chamo a atenção especialmente para o capítulo intitulado "Ascensão do bacharel e do mulato" presente em Sobrados e Mucambos, obra publicada em 1936. Na análise do autor, os processos de transformações sociais possibilitaram que a relação entre educação e raça alcançasse outro patamar, uma vez que no Brasil imperial por meio da escolarização os mulatos e negros, principalmente os primeiros, por meio seus estudos e tornavam-se socialmente iguais aos filhos das mais velhas e poderosas famílias de senhores de terra.

Uma nova lógica passou a se constituir, nesse momento, na passagem do século XVIII para o XIX, o requisito fundamental para determinados serviços, como os de caixeiros, não era mais que fossem brancos. O mais relevante para ocupar determinados postos teria passado a ser o título de bacharel e de doutor, o que não ocorreu necessariamente acompanhado pela demanda do "sangue rigorosamente limpo", ainda que "Salienta-se, entretanto que a ascensão social do bacharel, quando mulato evidente, só raramente ocorreu de modo menos dramático." (FREYRE, 2006, p. 723).

Algumas dessas questões já apareciam em sua dissertação de mestrado, trabalho elaborado ainda no início dos anos de 1920 nos Estados Unidos, ao afirmar que ante ao liberalismo do Império o mérito individual era reconhecido, mesmo quando se tratava de sujeitos de origem social modesta, incluindo aí filhos de escravos, que se valorizassem pelo casamento ou pela instrução superior (FREYRE, 2008).

Já em Ordem e Progresso, obra publicada em 1957, o autor vai além, ao afirmar que:

(...) desde o Império os títulos acadêmicos foram no Brasil meios de ascensão social que favoreceram particularmente os moços mestiços ou de origem modesta. Eram cartas de branquitude sociológica que os foram tornando iguais aos brancos de origem 
fidalga: às vezes seus superiores pelo talento e pelo saber aplicado à política, à advocacia, à medicina, ao sacerdócio, à engenharia: a atividades socialmente prestigiosas.

Esse processo de valorização do homem de origem modesta ou de condição étnica socialmente inferior, pelo título acadêmico, acentuou-se com o advento da República; e não apenas através das referidas academias ou escolas superiores, como através das academias ou escolas militares. Não tanto a da Marinha como a do Exército. Embora continuando, neste ponto, a obra do Império, e não propriamente inovando na matéria, a República avivou no Brasil as oportunidades de ascensão social, particularmente política, dos mestiços e dos plebeus. (FREYRE, 2004, p. 536).

Creio que nesse ponto nos encontramos diante de um nó em seu trabalho, pois, se por um lado fala-se em "cartas de branquitude sociológica", bem como de ascensão social por meio da instrução superior, significa, em última instância, que há o reconhecimento por parte do autor de que apesar do processo de miscigenação haveria desigualdades raciais no Brasil. Mas, por outro lado, considerando que a educação seria capaz de outorgar tais cartas, transpondo a dimensão racial, então a chave para a compreensão das desigualdades no Brasil seria a educação, mais que a raça. Neste ponto, é importante considerar que:

Em que pese a reacomodação das estruturas sociais ao longo do tempo, seria ante uma sociedade urbanizada que não apenas as oportunidades educacionais se ampliam, como também seu lugar é ressignificado, possibilitando que o acesso à instrução formal tenha um impacto sobre a estratificação social, porém, isso só seria possível, na interpretação do autor, dada a inexistência de barreiras étnicas, ou ao menos a fragilidade destas nos termos comparativos que ele se utiliza no 
Para além do mito da democracia racial: a questão educacional no pensamento de Gilberto Freyre

decorrer de toda sua obra para pensar o Brasil. (OLIVEIRA, 2016, p. 324).

Ainda que o autor esteja centrando sua análise em séculos anteriores, é válido rememorar que a compreensão que Freyre tem sobre o passado não é de um tempo longinquou e estático, muito pelo contrário, o passado teria um peso significativo sobre o presente e sobre nossas possibilidades de futuro.

Não compreendo que se possa solapar os argumentos elaborados pelo autor de forma simples, reduzindo-o ao defensor do "mito da democracia racial", pois penso que ficou evidente no caminho percorrido até aqui que seu trabalho não se assenta nessa perspectiva, o reconhecimento das desigualdades entre negros e brancos é evidente em seu trabalho. Freyre percebeu que poderíamos caminhar para este cenário, que estávamos mais próximo disso que outras nações, portanto, a ideia de uma democracia étnica possui sempre um valor relativo e comparativo em sua obra, mas que a educação seria uma condição sine qua non para tanto.

\section{Considerações Finais}

Este breve artigo não buscou exaurir a discussão em torno da obra de Freyre, nem mesmo sobre a questão educacional nela, entretanto tentei colocar em discussão pontos pouco explorados de seu legado, ainda que de forma bastante sucinta. A articulação aqui entre raça e educação, especialmente no segundo tópico, não foi fortuita, pois o próprio Freyre quando elaborou seu programa de Sociologia para as alunas da Escola Normal, portanto futuras professoras, incluiu entre os 17 temas um relativo a "O Problema da miscigenação no Brasil". Isto indica que ele considerava que tal temática era relevante para a formação docente, e por consequência para o campo educacional.

Acredito que estes aspectos têm passado despercebidos nas inúmeras revisitas que o trabalho de Freyre tem recebido nos últimos anos, o que se deve, em grande medida, ao parco interesse dos cientistas sociais de modo geral, e dos antropólogos em particular, pelo debate educacional ${ }^{7}$.

7 Não quero afirmar com isso que não haja interesse de alguns dos cientistas sociais (e mais ainda dos antropólogos) no debate educacional, mas sim que esta é uma temática pouco privilegiada na agenda de pesquisa desse campo. Todavia há de se ressaltar a atuação de 
Porém, creio que se considerarmos o atual cenário, marcado por uma crescente presença de políticas públicas em educação voltadas para a diversidade, poderemos perceber que as questões levantadas por este clássico da Antropologia brasileira continuam atuais.

Sua proposta pedagógica a partir de uma forte articulação entre o mundo social e os conhecimentos teóricos continua atual. Acredito que necessária para pensarmos numa escola que consiga dialogar com os jovens que nela se encontram. Tanto com relação a esta questão, quanto com relação ao debate racial a impressão que tenho é que Freyre não está superado, muito pelo contrário, parece-me que a sociedade brasileira ainda está em um período pré-freyreanao, com escolas que tendencialmente apartam o mundo social dos alunos dos conhecimentos que são aprendidos entre seus muros, e uma percepção bastante estreita sobre mestiçagem cultural.

Volto a pensar que a partir de Freyre podemos afirmar que o processo de consolidação de uma democracia no país, étnica e social, perpassa necessariamente o nosso dilema educacional. Em Freyre, conforme entrevista concedida a Lêda Rivas em 15 de março de 1980, ele chama a atenção para a íntima relação entre os problemas de classe, raça, culturais e educacionais na sociedade brasileira, indagando quem depois do "festivo e retórico 13 de maio" cuidou da educação no negro. Longe de negar os preconceitos e processos de exclusão em nossa sociedade, Freyre compreende que para analisá-los no Brasil há de se considerar os múltilplos fatores envolvidos na questão, havendo um especial destaque para o educacional.

\section{Referências}

BASTOS, Elide Rugai. As Criaturas de Prometeu: Gilberto Freyre e a formação da sociedade brasileira. São Paulo: Global, 2006.

BOMENY, Helena. Os Intelectuais da Educação. Rio de Janeiro: Zahar Ed, 2003.

tais profissionais em debates relevantes como no que diz respeito à educação escolar indígena, às ações afirmativas, e às questões envolvendo diversidade religiosa, de gênero e sexualidade nas escolas.

8 Disponível em <http://bvgf.fgf.org.br/portugues/vida/entrevistas/anarquista.html> 
Para além do mito da democracia racial: a questão educacional no pensamento de Gilberto Freyre

BRASIL. Lei no 10.639 de 9 de janeiro de 2003. Altera a Lei no 9.394, de 20 de dezembro de 1996, que estabelece as diretrizes e bases da educação nacional, para incluir no currículo oficial da Rede de Ensino a obrigatoriedade da temática "História e Cultura Afro-Brasileira", e dá outras providências. . Diário Oficial da União, Brasília, 10 de janeiro 2003.

BURKE, Peter. Gilberto Freyre e a nova história. Tempo soc., v. 9, n. 2, p.1-12, 1997.

CARDOSO, Fernando Henrique. Pensadores que Inventaram o Brasil. São Paulo: Companhia das Letras, 2013.

FREYRE, Gilberto. Casa Grande E Senzala: formação da família brasileira sob o regime da economina patriarcal. São Paulo: Global, 2005.

. Como e porque sou e não sou sociólogo. Brasília: Editora Universidade de Brasília, 1968.

- Interpretação do Brasil: aspectos da formação social brasileira como processo de amalgamento de raças e culturas. São Paulo: Companhia das Letras, 2001.

. Novo Mundo nos Trópicos. São Paulo: Global, 2011.

. O Anarquista de Apipucos. [15 de março, 1980]. Recife: Parceiros do

Tempo. Entrevista concedida a Lêda Rivas. Disponível em $<$ http://bvgf.fgf.org.br/portugues/vida/entrevistas/anarquista.html $>$ último acesso em 16 de jun. de 2015.

. O Estudo das Ciências Sociais nas Universidades Americanas. Recife:

Edições Momento, 1934.

Ordem \& Progresso: processo de desintegração das sociedades patriarcal e semipatriarcal no Brasil no Brasil sob o regime de trabalho livre: aspectos de um quase meio-século de transição do trabalho escravo para o trabalho livre; e da monarquia para a república. São Paulo: Global, 2004.

- Palavras às Professoras Rurais do Nordeste. Recife: Secretaria de Educação e Cultura, 1957.

. Palavras Repatriadas. Brasília: Editora da Universidade de Brasília, 2003.

Problemas Brasileiros de Antropologia. Rio de Janeiro: Livraria José Olympio Editora, 1973.

- Sobrados $\mathcal{E}$ Mucambos: decadência do patriarcado e desenvolvimento do

urbano. Global: São Paulo, 2006. 2009.

. Sociologia: introdução ao estudo dos seus princípios. São Paulo: Global, 
Vida Social no Brasil nos Meados do Século XIX. São Paulo, 2008.

GUSMÃO, Neusa Maria Mendes. Entrelugares: antropologia e educação no Brasil. Revista Educação (UFSM). V, 34, n. 1, p. 29-46, 2009.

LEHMANN, David. Gilberto Freyre: a reavaliação prossegue. Horiz. antropol., v. 14, n. 29, p.369-385, 2008.

LARRETA, Enrique Rodriguez; GIUCCI, Guillermo. Gilberto Freyre: uma biografia cultural. Rio de Janeiro: Civilização Brasileira, 2007.

MEUCCI, Simone. Artesania da sociologia no Brasil: contribuições e interpretações de Gilberto Freyre. Curitiba: Appris, 2015a.

- Gilberto Freyre no comando do Centro Regional de Pesquisas Educacionais do Recife: o debate sobre educação (1957-1964). Sociologia $\mathcal{E}$ Antrolopologia, v. 5, n.1, p. 129-155, 2015b.

MOTTA, Roberto. Élide, Gilberto, Imagismo e Língua de Universidade. Revista Brasileira de Ciências Sociais, v. 24, n. 69, p. 185-206, 2009.

. Paradigmas de Interpretação das Relações Raciais no Brasil. Estudos Afro-Asiáticos, s/v, n. 38, p. 113-134, 2000.

. Reação a Max Weber no Pensamento Brasileiro: O Caso de Gilberto Freyre. Estudos de Sociologia, v., 13, n. 1, p. 185-206, 2008.

MOTTA, Roberto; FERNANDES, Marcionilia. “Gilberto Freyre, um enigma genealógico". In: (Ogs.) Gilberto Freyre: região, tradição, trópico e outras aproximações. Rio de Janeiro: Instituto Miguel de Cervantes. p. 11-36, 2013.

PALLARES-BURKE, Maria Lúcia. Gilberto Freyre - um vitoriano nos trópicos. São Paulo: Editora UNESP, 2005.

PALLARES-BURKE, Maria Lúcia; BURKE, Peter. Repensando os Trópicos: um retrato intelectual de Gilberto Freyre. São Paulo: Editora UNESP, 2009.

OLIVEIRA, Amurabi. A Meninice no Pensamento de Gilberto Freyre. Política \& Trabalho, s/v, n. 43, p. 203-218, 2015a.

A Relação entre Raça e Educação na Obra de Gilberto Freyre. Universitas Humanisticas, v. 81, n. 81, p. 305-329, 2016.

Educação e Pensamento Social Brasileiro: alguns apontamentos a partir de Florestan Fernandes e Gilberto Freyre. Revista de Ciências Sociais , v. 45 , n. 1, p. 15-44, 2014.

. O lugar da antropologia na formação docente: um olhar a partir das escolas normais. Pro-Posições, v. 2, n. 2, p. 27-40, 2013.

SILVA, Graziella Moraes Dias da. Sociologia da Sociologia da Educação: caminhos e desafios de uma policy science no Brasil (1920-1979). Bragança 
Para além do mito da democracia racial: a questão educacional no pensamento de Gilberto Freyre

Paulista: EDUSF, 2002.

VILLAS BOAS, Glaucia. Mudança Provocada: passado e futuro no pensamento sociológico brasileiro. Rio de Janeiro: Editora FGV, 2006.

Enviado em: 23/10/2015

Aceito em: $\quad$ 11/06/2016 